\title{
Editorial
}

\section{Taming platelets in coronary stenting: ticlopidine out, clopidogrel in?}

The use of intracoronary stents has revolutionised percutaneous myocardial revascularisation by reducing the need for urgent surgical intervention and decreasing long term restenosis rates to approximately $15 \% .^{1-4}$ The early use of these devices was complicated by high rates of acute and subacute thrombosis requiring intensive anticoagulation regimens, which were only partially effective at reducing their incidence. ${ }^{5}$ The importance of the platelet, rather than the coagulation cascade, in the pathogenesis of these complications was confirmed when Schömig et al reported an $82 \%$ reduction in myocardial infarctions with a combination of aspirin and ticlopidine compared to heparin, phenprocoumon, and aspirin in patients receiving coronary artery stents. ${ }^{6}$ Since that time aspirin and ticlopidine have been widely used following stent insertion for four weeks to six months, with reported composite end points of death, myocardial infarction, and revascularisation, of $0-1.9 \%$ in the first 30 days. ${ }^{6-8}$

\section{Ticlopidine}

The rationale for combining aspirin and ticlopidine is derived from their different mechanisms of action, which may potentiate one another. Aspirin produces permanent inhibition of the cyclo-oxygenase pathway thus reducing production of thromboxane $\mathrm{A}_{2}$, prostaglandin $\mathrm{E}_{2}$, and prostacyclin. Ticlopidine inhibits ADP induced platelet aggregation by selective, irreversible, and competitive binding to the type 2 purinergic ADP receptor. In vivo studies on platelet function have demonstrated that the combination of aspirin and ticlopidine has a greater effect on platelet aggregation than either agent alone. ${ }^{9}{ }^{10}$ It is still unclear, however, whether this dual effect translates into a significant clinical benefit for all coronary stent patients, as several non-randomised studies have reported that aspirin or ticlopidine alone may be adequate to prevent acute stent thrombosis. ${ }^{81112}$ It must be emphasised that these studies optimised stent deployment using ultrasound guidance and high pressure balloon dilatation, which are not routine practice in the UK and there is still a general unease about coronary stenting using aspirin alone.

The success of this antiplatelet combination has been tempered to some extent by the frequent side effects of ticlopidine. Severe neutropenia is the most serious of these and occurs in $0.7-1.2 \%{ }^{4}$ of patients with up to six months of continuous treatment and $4 \%$ of patients with five years ${ }^{13}$ of treatment. In most patients, this complication is reversible with cessation of ticlopidine, but a recent study reported that eight of 19 patients with ticlopidine induced neutropenia died as a result of sepsis despite aggressive treatment with granulocyte colony stimulating factor. ${ }^{14}$ Furthermore, the incidence of other side effects such as skin rashes, gastrointestinal disturbance, and renal dysfunction is reported to be $7 \%$ in patients on a six week course, ${ }^{4}$ and $22 \%$ in those taking ticlopidine for five years. ${ }^{13}$ The clear message from these studies is that if ticlopidine is to be used it should be for as short a time as possible.

\section{Clopidogrel}

The recently presented preliminary data from the CLASSICS trial (clopidogrel aspirin stent international cooperative study; American College of Cardiology, New Orleans, USA, 1999) suggest that clopidogrel can be used as an effective alternative to ticlopidine (fig 1). Clopidogrel is a thienopyridine analogue of ticlopidine with a similar mechanism of action. Experimental studies have suggested that a dose of $75 \mathrm{mg}$ clopidogrel is equivalent, in terms of platelet aggregation inhibition, to $500 \mathrm{mg}$ of ticlopidine and may be even more effective in preventing high shear mediated stent thrombosis. ${ }^{15}$

The CLASSICS study examined three groups of 335 patients undergoing coronary artery stenting and compared aspirin and two different clopidogrel regimens with aspirin and ticlopidine (fig 1). The study was not powered to detect differences in major adverse cardiac events but was designed to examine the safety, in terms of side effects, of the aspirin and clopidogrel combination. The CAPRIE trial (clopidogrel versus aspirin in patients at risk of ischaemic events) ${ }^{16}$ in 19000 patients showed that clopidogrel alone is as well tolerated as aspirin, but the safety of the aspirin-clopidogrel combination had not been tested. In the CLASSICS trial, the combined results from the two clopidogrel groups with $325 \mathrm{mg}$ of aspirin produced significantly fewer complications than $325 \mathrm{mg}$ aspirin and $250 \mathrm{mg}$ ticlopidine bid $(4.56 \% v 9.12 \%$; $=0.005)$. Of note was the finding that the loading dose produced no more complications than the standard dose of $75 \mathrm{mg}$ of

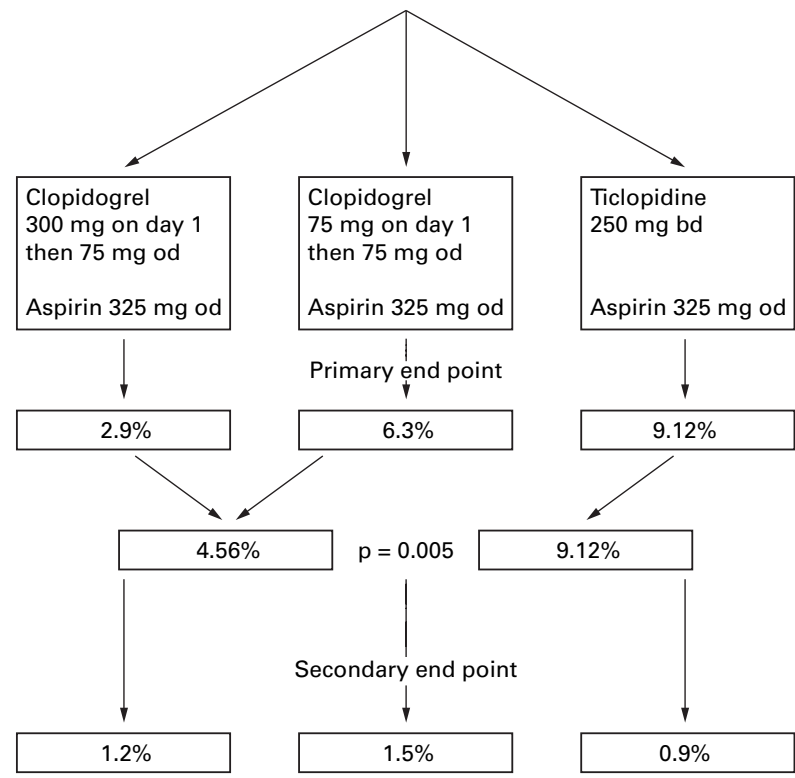

$p>0.05$ for comparison of all groups

Figure 1 Design and results of the CLASSICS trial: 335 patients in each group were treated for 28 days. Primary end point: cluster of major bleeding, neutropenia, thrombocytopenia, and other early discontinuation for non-cardiac cause. Secondary end point: cluster of major cardiac events (myocardial infarction, sudden death, subacute thrombosis). 
clopidogrel. The analysis of the secondary end point of major adverse cardiac events produced a non-significant difference between the groups with an event rate in the aspirin and ticlopidine group of $0.9 \%$ and in the aspirin and clopidogrel loading group of $1.2 \%$. Even though the numbers are small and there is a lack of any good comparative efficacy data, the event rate of approximately $1 \%$ in both groups does compare favourably with other studies of coronary stenting. ${ }^{6-8}$

Clopidogrel also has the advantage of being less expensive than ticlopidine: a one month course at $75 \mathrm{mg}$ daily costs approximately $£ 30$ (US $\$ 48$ ) whereas a similar course of ticlopidine at $250 \mathrm{mg}$ bid costs approximately $£ 90$ (US\$144).

\section{Conclusions}

Given the favourable side effect profile, the lower cost, and likely equivalence to ticlopidine in coronary stenting, the time has probably come for clopidogrel and aspirin to become the first choice regimen for post-stent patients. Ticlopidine would then be reserved for those who cannot tolerate clopidogrel. For those who require hard evidence-based guidelines, however, the jury is still out.

C I O BROOKES U SIGWART

Department of Invasive Cardiology, Royal Brompton Hospital, London SW3 6NP, UK email:u.sigwart@rbh.nthames.nhs.uk

1 Sigwart U, Puel J, Mirkovitch V, et al. Intravascular stents to prevent occlusion and restenosis after transluminal angioplasty. $N$ Engl $f$ Med 1987;316:701-6.
2 Serruys PW, de Jaegare P, Kiemeneij F, et al. A comparison of balloon-expandable-stent implantation with balloon angioplasty in patients with coronary artery disease. N Engl f Med 1994;331:489-95.

3 Fischman DL, Leon MB, Baim DS, et al. A randomised comparison of coronary-stent placement with balloon angioplasty in the treatment of coronary artery disease. $\mathrm{N} \mathrm{Engl} \mathrm{F} \mathrm{Med} \mathrm{1994;331:496-501.}$

4 Berger PB, Bell MR, Grill DE, et al. Frequency of adverse clinical events in the 12 months following successful coronary artery stent placement in patients treated with aspirin and ticlopidine. Am $\mathcal{F}$ Cardiol. 1998;81:713patien.

5 Eeckhout E, Kappenberger L, Goy JL. Stents for intracoronary placement: current status and future directions. F Am Coll Cardiol 1996;27:757-65.

6 Schömig A, Neumann FJ, Kastrati A, et al. A randomised comparison of antiplatelet and anticoagulation therapy after the placement of coronary artery stents. N Engl f Med 1996;334:1084-9.

7 Leon MB, Baim DS, Popma JJ, et al. A clinical trial comparing three antithrombotic drug regimens after coronary artery stenting (STARS). $N$ Engl.f Med 1998;339:1665-71.

8 Albiero R, Hall P, Itoh A, et al. Results of a consecutive series of patients receiving only antiplatelet therapy after optimized stent implantation. Circulation 1997;95:1145-56.

9 Neumann FJ, Gawaz M, Dickfeld T, et al. Antiplatelet effect of ticlopidine after coronary stenting. F Am Coll Cardiol 1997;29:1515-19.

10 Rupprecht HJ, Darius H, Borkowski U, et al. Comparison of the antiplatelet effects of aspirin, ticlopidine or their combination after stent implantation. Circulation 1998;97:1046-52.

11 Elsner M, Peifer A, Drexler M, et al. Clinical outcome at six months of coronary stenting followed by ticlopidine monotherapy. Am 7 Cardiol 1998;81: 147-51.

12 Barragan P, Sainsous J, Silvestri M, et al. Coronary artery stenting without anticoagulation, aspirin, ultrasound guidance, or high balloon pressure: a prospective study of 1051 consecutive patients. Cathet Cardiovasc Diagn 1997;42:367-73.

13 Janzon L. The STIMS trial: the ticlopidine experience and its clinical applications. Swedish ticlopidine multicenter study. Vascular Medicine 1996;1: 141-3.

14 Yeh SP, Hsueh EJ, Wu $\mathrm{H}$, et al. Ticlopidine associated aplastic anaemia A case report and review of the literature. Ann Haematol 1998;76: 87-90.

15 Makkar R, Eigler N, Kaul S, et al. Clopidogrel, a novel platelet ADP-receptor antagonist inhibits aspirin and ticlopidine-resistant stent thrombosis [abstract]. 7 Am Coll Cardiol 1997;29(suppl A):353A

16 CAPRIE Steering Committee. A randomised blinded trial of clopidogrel versus aspirin in patients at risk of ischaemic events (CAPRIE). Lancet 1996;348:1329-39.

\section{Editorial}

\section{Should we ever treat the echo rather than the patient?}

It is not unusual to find a Doppler derived peak gradient of $40 \mathrm{~mm} \mathrm{Hg}$ across a Bjork-Shiley valve in the aortic position. However, in the case reported below ${ }^{1}$ further investigation led to the identification of thrombus, and the patient underwent reoperation despite being asymptomatic. Should this case affect our management of mechanical valves?

Most centres perform routine postoperative echocardiography. This is useful to compare with future studies as a new paraprosthetic leak may be a sign of endocarditis, and a major change in forward flow pattern may support the clinical suspicion of obstruction. However, published guidelines ${ }^{2}{ }^{3}$ do not recommend further studies unless the patient has symptoms or there is clinical suspicion of valve dysfunction. According to these guidelines, the study ultimately leading to surgery in this patient need not have been performed. We do not know if this would have mattered. The patient might have remained asymptomatic. Alternatively, the thrombosis could have progressed leading to symptomatic severe obstruction, an embolic event or even death.

Thrombosis of mechanical valves in the aortic position is exceptionally rare. ${ }^{4}$ It is therefore unlikely that many lives would be saved by routine echocardiography in all patients.
On the contrary, it is more likely that lives would be endangered as a result of replacing valves unnecessarily on the suspicion of obstruction incorrectly diagnosed from the echocardiogram; surgery based largely or exclusively on gradient alone has occurred anecdotally. In this case report the echocardiogram was clearly abnormal. The disk probably opened incompletely and the peak gradient had doubled compared with previous studies and was well above the published $95 \%$ upper limit of $30 \mathrm{~mm} \mathrm{Hg}$ (Chambers JB, unpublished data, 1990) ${ }^{56}$ for a valve of this size and type. However, a peak gradient of $40 \mathrm{~mm} \mathrm{Hg}^{1}$ could be normal for a $23 \mathrm{~mm}$ or smaller Björk-Shiley valve (Chambers JB, unpublished data, 1990). ${ }^{5}$ For a $19 \mathrm{~mm}$ St Jude or Carbomedics valve a peak gradient as high as $60 \mathrm{~mm} \mathrm{Hg}$ could be normal. ${ }^{78}$ Thus, an apparently high individual velocity or derived gradient requires careful interpretation in relation to the valve type and size, to previous studies in the same patient, and in the context of left ventricular function and symptoms before clinical management is changed.

The risk of mechanical thrombosis is so close to $0^{4}$ that if a patient is well the valve can usually be assumed to be normal. The present case ${ }^{1}$ is a rare exception and routine echocardiography of asymptomatic patients with clinically normal mechanical valves is not necessary. 
Cardiothoracic Centre, St Thomas' Hospital, London SE1 7EH, UK

email:johnchambers@dial.pipex.com

1 Dennig K, Lehmann G. Thrombosis of an aortic valve prosthesis. Heart 1999;82:653.

2 Cheitlin MD, Alpert JS, Armstrong WF, et al. ACC/AHA guidelines for the clinical application of echocardiography: executive summary. $\mathcal{F} \mathrm{Am}$ Coll Cardiol 1997;29:862-79.

3 Chambers J, Fraser A, Lawford P, et al. The echocardiographic assessment of artificial heart valves: British Society of Echocardiography position paper. Br Heart 7 1994;71 (suppl):6-14.
4 Grunkemeier GL, Starr A, Rahimtoola SH. Prosthetic heart valve performance: long-term follow-up. Current Problems in Cardiology 1992;17:

5 Ramirez ML, Wong M, Sodlder N, et al. Doppler evaluation of bioprosthetic and mechanical aortic valves: Data from four models in 107 stable ambulatory patients. Am Heart f 1988;115:418-25.

6 Sagar KB, Wann LS, Paulsen WHJ, et al. Doppler echocardiographic evaluation of Hancock and Bjork-Shiley prosthetic valves. $\mathcal{F}$ Am Coll Cardiol 1986;7:681-7

7 Globits S, Rodler S, Mayr H, et al. Doppler sonographic evaluation of the CarboMedics bileaflet valve prosthesis: one year experience. $\mathcal{F}$ Cardiac Surg 1992;7:9-16.

8 Ren JF, Chandrasekaran K, Mintz GS, et al. Effect of depressed left ventricular function on hemodynamics of normal St Jude Medical prostheses in the aortic valve position. Am f Cardiol 1990;65:1004-9.

\section{IMAGES IN CARDIOLOGY}

\section{Thrombosis of an aortic valve prosthesis}

A 66 year old woman had undergone aortic valve replacement (Björk-Shiley standard prosthesis, size 27) 23 years earlier because of severe aortic stenosis. She had since been asymptomatic and all outpatient examinations showed normal prosthetic function. She had recently undergone surgery for haemorrhoids, which required anticoagulation to be interrupted and bridged by once daily subcutaneous injections of low molecular heparin. A peak pressure gradient of $40 \mathrm{~mm} \mathrm{Hg}$ was measured across the prosthesis on transthoracic Doppler echocardiography. Based on a similar heart rate, this was double that of a previous examination; therefore, obstruction of the prosthetic valve was suspected.

Transoesophageal echocardiography showed thrombotic material adjacent to the prosthesis. A cross sectional view through the aortic root revealed thrombi (arrowed) localised at the prosthetic ring protruding into the lumen. A long axis view of the ascending aorta showed flow exclusively across the major orifice by colour Doppler (not shown). The thrombotic prosthesis was excised and replaced with a bileaflet aortic valve prosthesis; her recovery was uneventful.
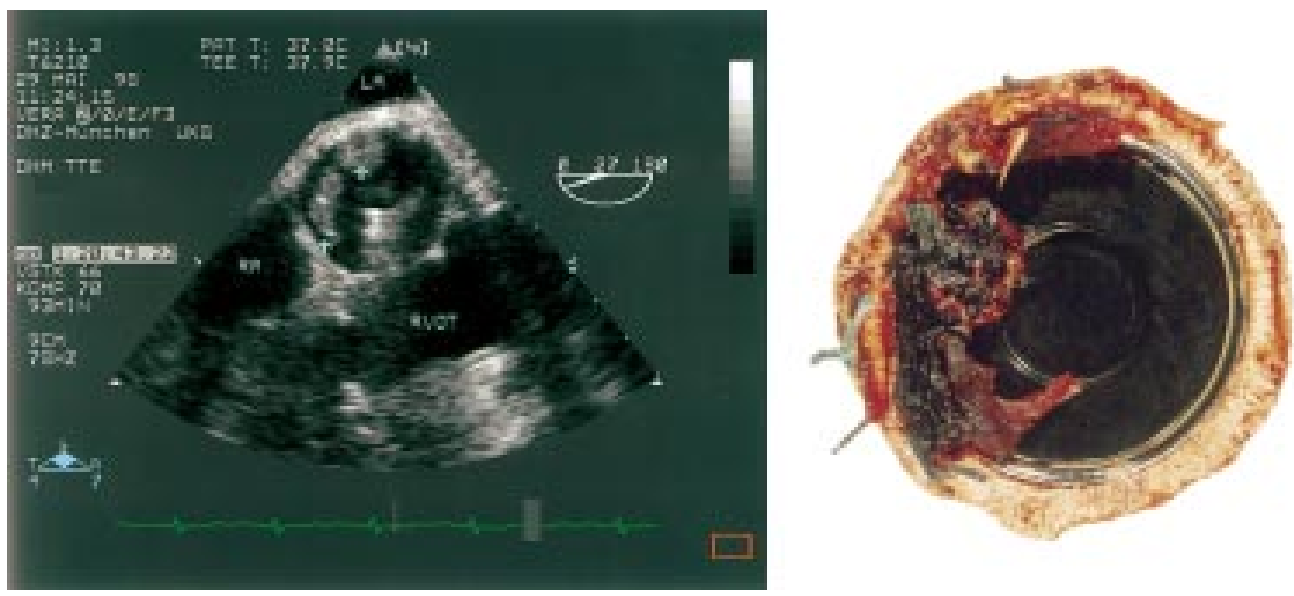

KARL DENNIG GÜNTER LEHMANN 